\title{
Transcriptome analysis of peripheral blood from patients with rheumatoid arthritis: a systematic review
}

\author{
Shuji Sumitomo', Yasuo Nagafuchi', Yumi Tsuchida', Haruka Tsuchiya', Mineto Ota', Kazuyoshi Ishigaki², \\ Akari Suzuki $^{3}$, Yuta Kochi ${ }^{3}$, Keishi Fujio ${ }^{1 *}$ and Kazuhiko Yamamoto ${ }^{4}$
}

\begin{abstract}
In the era of precision medicine, transcriptome analysis of whole gene expression is an essential technology. While DNA microarray has a limited dynamic range and a problem of background hybridization, RNA sequencing (RNA-seq) has a broader dynamic range and a lower background signal that increase the sensitivity and reproducibility. While transcriptome analyses in rheumatoid arthritis (RA) have generally focused on whole peripheral blood mononuclear cells (PBMC), analyses of detailed cell subsets have an increased need for understanding the pathophysiology of disease because the involvement of $\mathrm{CD}^{+} \mathrm{T}$ cells in the pathogenesis of RA has been established. Transcriptome analysis of detailed $\mathrm{CD}^{+} \mathrm{T}$ cell subsets or neutrophils shed new light on the pathophysiology of RA. There are several analyses about the effect of biological treatment. Many studies report the association between type I interferon signature gene expression and response to therapy.
\end{abstract}

Keywords: Rheumatoid arthritis, Transcriptome analysis, RNA sequencing (RNA-seq)

\section{Background}

Rheumatoid arthritis (RA) is an autoimmune disease characterized by chronic inflammatory synovitis and progressive disability. Environmental factors including smoking [1] and periodontitis, epigenetic modification, and susceptibility genes [2] generate self-proteins with a citrulline residue by post-translational modification. Breakdown of immunological tolerance to citrullinated self-proteins is considered to be an important feature of RA pathogenesis [3]. This anticitrulline response can be detected in $\mathrm{T}$ cell and $\mathrm{B}$ cell compartments and is probably initiated in secondary lymphoid tissues or bone marrow. Thereafter, synovitis occurs when leukocytes infiltrate the synovial compartment [4]. Synovium is the principal target of inflammation in RA, and the resident fibroblast-like synoviocytes (FLSs) are implicated in the pathogenesis of synovitis [5].

There is much interest in transcriptome analysis as a mechanism for predicting RA pathogenesis and effect of

\footnotetext{
*Correspondence: kfujio-tky@umin.ac.jp

'Department of Allergy and Rheumatology, Graduate School of Medicine, the University of Tokyo, 7-3-1 Hongo, Bunkyo-ku, Tokyo 113-8655, Japan Full list of author information is available at the end of the article
}

treatment. Gene expression profiling is a quantitative measurement of messenger RNA levels for thousands of genes at once, to create a global picture of cellular function and contribute to the era of stratified medicine [6]. DNA microarrays have been used to drive genetic analyses for more than two decades. However, microarrays have limited dynamic range that often prevents accurate assessment of low signal intensities, and suffer from the problem of background hybridization. Such limitations are largely absent in RNA sequencing (RNA-seq), a next-generation sequencing (NGS) method largely used for the genome-wide measurement of RNA abundance. Compared with microarrays, RNA-seq has several advantages, such as low background signal, a broader dynamic range, increased sensitivity, and high reproducibility [7].

Transcriptome analyses in RA generally focused on whole peripheral blood mononuclear cells (PBMC) $[8,9]$. However, the importance of cell-type specificity is becoming increasingly apparent in gene expression work. Cell-type specificity would be missed in whole blood samples, especially when investigating low abundance genes. Moreover, dynamic variations in leukocyte subsets may confound the interpretation of results [6]. 
Transcriptome analyses also contribute to the understandings of the effect of treatment. For example, transcriptome analysis revealed that type I interferon (IFN) signature genes were particularly associated with clinical response to bDMARDs including TNF- $\alpha$ inhibitor [10], tocilizumab [8], and rituximab [9]. In the analysis of the effect of treatment, samples must be taken at the same time points and from the same source in order to lead biologically meaningful comparative transcriptome analyses. Moreover, longitudinal studies may yield more relevant answers compared to cross-sectional studies.

In this review, we discuss the transcriptome analysis of various cell subsets in PBMC of RA and analysis about the effect of biological treatment.

\section{Main text \\ $\mathrm{CD}^{+} \mathrm{T}$ cells}

The involvement of $\mathrm{CD}^{+} \mathrm{T}$ cells in the pathogenesis of RA has been established based on the fact that HLA-DRB1 genotype is by far the strongest genetic risk factor for RA [2]. Moreover, RA genetic risk loci preferentially map to enhancers and promoters active in $\mathrm{CD}^{+}{ }^{+} \mathrm{T}$ cell subpopulations [11]. We conducted expression quantitative trait loci (eQTL) analysis on five subsets of immune cells $\left(\mathrm{CD}^{+}{ }^{+} \mathrm{T}\right.$ cells, $\mathrm{CD} 8^{+} \mathrm{T}$ cells, B cells, natural killer (NK) cells, and monocytes) and unfractionated peripheral blood from 105 healthy Japanese volunteers. We developed a three-step analytical pipeline comprising (i) prediction of individual gene expression using our eQTL database and public epigenomic data, (ii) gene-level association analysis, and (iii) prediction of cell-specific pathway activity by integrating the direction of eQTL effects. By applying this pipeline to RA GWAS data sets, the tumor necrosis factor (TNF) pathway was predicted to be significantly activated, specifically in $\mathrm{CD}^{+}{ }^{+} \mathrm{T}$ cells [12].

Ye et al. examined the whole-genome transcription profile of $\mathrm{CD}^{+}{ }^{+} \mathrm{T}$ cells in RA compared with healthy individuals using microarray analysis [13]. They reported that $\mathrm{CD}^{+}{ }^{+} \mathrm{T}$ cells from patients with RA have abnormal functional networks in STAT3 signaling and Wnt signaling. Their results also suggested that the aberrant expression of several zinc finger transcription factors (ZEB1, ZNF292, and ZNF644) may be potential pathogenic factors for RA.

\section{$C D 4^{+} T$ cell subsets}

There are few reports for detailed transcriptome analysis of $\mathrm{CD}^{+}{ }^{+} \mathrm{T}$ cell subsets in RA. Although contributions of Th17 cells [14], regulatory $\mathrm{T}$ cells (Treg) [15], and follicular helper $\mathrm{T}$ cells (Tfh) [16] have been reported, the actual modifications of $\mathrm{CD}^{+} \mathrm{T}$ cells in RA have not been elucidated. We performed RNA-seq of seven CD4 ${ }^{+}$ $\mathrm{T}$ cell subsets (naive, Th1, Th17, Th1/17, nonTh1/17, Tfh, and Treg) of peripheral blood taken from RA patients and healthy controls ( $\mathrm{HC})[17])$. We found that several pathways including GTPase-associated signaling and apoptosis signaling were upregulated in RA as previously reported $[18,19]$. Weighted gene co-expression network analysis (WGCNA) [20] identified a gene module that consisted of 227 genes and was correlated with DAS28-CRP. The most highly connected 30 genes of this module included ZAP70 and JAK3, and pathway analysis of this module revealed dysregulation of the TCR signaling pathway network.

\section{Co-stimulatory molecules}

Abatacept is a fusion protein composed of the Fc region of immunoglobulin and the extracellular domain of CTLA-4 that inhibits $\mathrm{T}$ cell activation by blocking co-stimulation [21]. We performed RNA-seq of seven $\mathrm{CD}^{+} \mathrm{T}$ cell subsets (naive, Th1, Th17, Th1/17, nonTh1/17, Tfh, and Treg) of peripheral blood taken from RA patients before and 6 months after abatacept treatment [17]. Overview of expression pattern of RA revealed that administration of abatacept exerts a large shift toward the expression pattern of healthy control. Knowledge-based pathway analysis revealed the upregulation of activation-related pathways in RA that was substantially ameliorated by abatacept. We found that dysregulated TCR signaling pathways in RA were detected in RA through $\mathrm{CD}^{+}{ }^{+} \mathrm{T}$ cell subsets and ameliorated by abatacept treatment.

\section{B cells}

Rituximab is monoclonal anti-CD20 antibody and used to treat RA and B cell non-Hodgkin's lymphoma although RA treatment has not been approved in Japan. Sellam et al. performed microarray of whole peripheral blood samples of RA patients before and 24 weeks after treatment of rituximab [9]. They detected signature 143 genes for response featured upregulation of inflammatory genes centered on NF-kB, including IL33 and STAT5A, and downregulation of the IFN pathway. This signature accurately identifies patients with RA who will not respond to rituximab therapy. Raterman et al. also performed microarray of whole peripheral blood samples and found that the baseline expression of type I IFN response genes (LY6E, HERC5, IFI44L, ISG15, MxA, MxB, EPSTI1, and RSAD2) could be useful as a predictive biomarker for non-response to rituximab in RA [22]. Relationship between the type I IFN signature and the response to rituximab in RA had been reported by others [23, 24].

\section{Neutrophils}

Wright et al. performed RNA-Seq of RA neutrophils to identify pre-therapy gene expression signatures that correlate with disease activity or response to TNF inhibitor (TNFi) therapy [10]. Pathway analysis predicted activation of IFN signaling in RA neutrophils, identifying 178 IFN-response genes regulated by IFN- $\alpha$, IFN- $\beta$, or IFN- $\gamma$. 
Patients could be categorized as IFN-high or IFN-low. Patients in the IFN-high group achieved a better response to TNFi therapy than patients in the IFN-low group. IFN-response genes are significantly upregulated in RA neutrophils compared with healthy controls. Higher IFN-response gene expression in RA neutrophils correlates with a good response to TNFi therapy.

\section{Proinflammatory cytokines}

Koczan et al. performed microarray of PBMC of RA patients before the first application of the TNF $\alpha$ blocker etanercept as well as after $72 \mathrm{~h}$ [25]. Early downregulation of expression levels was associated with good clinical responses. Informative gene sets include genes (NFKBIA, CCL4, IL8, IL1B, TNFAIP3, PDE4B, PPP1R15A, and ADM) involved in different pathways and cellular processes such as TNF $\alpha$ signaling via NFkB; Van Baarsen et al. performed microarray of PBMC of RA patients before and 1 month after infliximab treatment [26]. While the change in IFN response genes was unrelated to baseline expression levels, treatment-induced increase of IFN response gene activity was associated with poor clinical response to infliximab treatment.

Sanayama et al. performed genome-wide DNA microarray of PBMC of RA patients before and after treatment with an anti-IL-6 receptor antibody, tocilizumab [8]. They found that three type I IFN response genes (IFI6, MX2, and OASL) and MT1G was significantly different between nonresponders and responders. MT1G encodes metallothionein-1G, a member of the metallothionein (MT) proteins that are involved in protection against oxidative stress and inflammatory responses. The MT-1 promoter contains a STAT binding site, and the gene expression of MT-1 is directly upregulated by IL-6. They suggested that type I IFN signaling and metallothioneins are involved in the pathophysiology of RA. Saito et al. performed microarray of $\mathrm{CD}^{+}{ }^{+} \mathrm{T}$ cells before and after treatment with tocilizumab [27]. They found that ARID-5A was downregulated by tocilizumab therapy. ARID-5A was a lineage-specific attenuator of Th17 cell differentiation and might be involved in the pathogenesis of RA.

\section{Future perspective}

While we have reviewed transcriptome analysis of peripheral blood from RA patients, there are several reports of specimens other than peripheral blood, mainly synovial tissue [28] and FLS [29]. Dennis et al. revealed that baseline synovial myeloid, but not lymphoid, gene signature expression was higher in patients with good compared with poor clinical response to anti-TNF $\alpha$ therapy [28]. Galligans et al. analyzed gene expression of FLS obtained from RA and osteoarthritis (OA), and identified 34 genes specific to RA and OA FLS, and 8 genes correlated with
RA disease activity. Epigenetic evaluation of FLS has also been extensively studied [30], and recently, Ai et al. reported comprehensive epigenetic landscape of RA FLS including histone modifications (H3K27ac, H3K4me1, H3K4me3, H3K36me3, H3K27me3, and H3K9me3), open chromatin, RNA expression, and whole-genome DNA methylation [31].

There are several reports concerning the effect of treatments other than biologic treatment on gene expression. Blits et al. investigated peripheral blood cells from methotrexate (MTX)-naïve and MTX-treated RA patients as well as from healthy controls. Concurrent with an immune activation gene signature, a significant upregulation of folate metabolizing enzymes (g-glutamyl hydrolase, dihydrofolate reductase), and MTX/folate efflux transporters (ABCC2 and ABCC5) was observed in MTX-naïve RA patients. Strikingly, MTX treatment normalized such differential gene expression levels to those observed in healthy controls [32]. Moreover, there is a report about effect of JAK inhibitor tofacitinib on gene expression of RA FLS [33]. Tofacitinib reduces matrix metalloproteinase (MMP)-1 and MMP-3 and IFN-regulated chemokines CCL2, CXCL10, and CXCL13 expression.

Type I IFNs are cytokines that regulate antiviral immune responses. Upregulation of type I IFN signature genes in RA $[8,10]$, and its relationship with therapeutic reactivity $[8,10,23,24]$ has been reported. The relationship between the type I IFN signature and the humoral autoimmune response in RA was analyzed in a number of previous studies. The presence of an IFN signature was associated with the persistence of ACPA after TNF blockade [26]. It has been hypothesized that patients with high activity of type I IFN may respond better to TNF blockade because of the anti-inflammatory effects of their disease-associated high levels of IFN $\beta$. Alternatively, patients with an IFN high signature may have an overall higher level of inflammatory activity than do patients with an IFN low signature and may respond better to TNF blockade because of the higher TNF $\alpha$ activity.

Okada et al. described that comprehensive genetic study sheds light on fundamental genes, pathways, and cell types that contribute to RA pathogenesis and provides important information for drug discovery [2]. On the other hand, merely gene expression analysis has a limitation for precision treatment for RA, for example, upregulation of type I IFN signature gene were detected commonly in autoimmune disease including RA, systemic lupus erythematosus [34], dermatomyositis [35], and systemic sclerosis [36]. It is necessary to increase the number of patients for analysis and to integrate more precise clinical information, genomic and epigenetic data, and gene expression data of various cell subsets. Recently, data of 1424 early RA patients from two consortia were combined to carry out a 
genome-wide study of response to MTX. The strongest evidence for association was with rs168201 in NRG3, and some support was also seen for association with ZMIZ1, previously highlighted in a study of response to MTX in juvenile idiopathic arthritis [37].

\section{Conclusion}

In the era of precision medicine, transcriptome analysis of whole gene expression is an essential technology. Analyses of detailed cell subsets should have an increased need for understanding the pathophysiology of disease. Careful and extensive consideration of study design is necessary for successful gene expression studies because gene expression is dependent on stages of the disease, time course of treatment, type of tissue, and cell types. While testing peripheral blood has been a standard transcriptome analysis of RA patients, it would be better to test synovial tissue, as this is the site of inflammation. The disadvantage of synovial tissue approach is that arthroplasty and blind needle biopsy had not been widely available, although the use of arthroscopic and ultrasonographic technologies has improved the reliability of synovial biopsies. Researchers will need to carefully consider the advantages of using peripheral blood samples to investigate.

\section{Abbreviations}

DAS28-CRP: Disease activity score- CRP; eQTL: Expression quantitative trait loci; FLS: Fibroblast-like synoviocyte; GWAS: Genome-wide association study; IFN: Interferon; MTX: Methotrexate; NGS: Next-generation sequencing; OA: Osteoarthritis; PBMC: Peripheral blood mononuclear cell; RA: Rheumatoid arthritis; RNA-seq: RNA sequencing; TCR: T cell receptor; Tfh: Follicular helper T cells; TNF: Tumor necrosis factor; Treg: Regulatory T cells;

WGCNA: Weighted gene co-expression network analysis

\section{Authors' contributions}

SS collected the entire literature and made the draft of the review. YN, YT, $\mathrm{HT}, \mathrm{MO}, \mathrm{Kl}, \mathrm{AS}, \mathrm{YK}$, and $\mathrm{KY}$ contributed to summarize literature and analyze and interpret our research results. KF revised the manuscript and gave final approval of the version to be published. All authors read and approved the final manuscript.

\section{Ethics approval and consent to participate}

Not applicable.

\section{Consent for publication}

Not applicable.

\section{Competing interests}

S.S. received honoraria from AbbVie, Eisai, Chugai, Takeda, Bristol-Myers Squibb, Astrazeneca and UCB. K.F. received speaking fees and/or honoraria from Astellas, Bristol-Myers Squibb, Daiichi-Sankyo, MitsubishiTanabe, Pfizer, Santen, Takeda, Chugai, Eisai, Taisho Toyama, UCB, and Janssen. K.Y. received speaking fees and/or honoraria from AbbVie, Astellas, Bristol-Myers Squibb, Daiichi-Sankyo, MitsubishiTanabe, Pfizer, Sanofi, Santen, Takeda, Teijin, Boehringer Ingelheim, Chugai, Eisai, Ono, Taisho Toyama, UCB, ImmunoFuture, Asahi Kasei, and Janssen. All other authors declare no competing financial interests.

\section{Publisher's Note}

Springer Nature remains neutral with regard to jurisdictional claims in published maps and institutional affiliations.

\section{Author details}

'Department of Allergy and Rheumatology, Graduate School of Medicine, the University of Tokyo, 7-3-1 Hongo, Bunkyo-ku, Tokyo 113-8655, Japan. ${ }^{2}$ Laboratory for Statistical Analysis, Center for Integrative Medical Sciences, the Institute of Physical and Chemical Research (RIKEN), 1-7-22 Suehirocho, Tsurumi-ku, Yokohama City, Kanagawa 230-0045, Japan. ${ }^{3}$ Laboratory for Autoimmune Diseases, Center for Integrative Medical Sciences, the Institute of Physical and Chemical Research (RIKEN), 1-7-22 Suehirocho, Tsurumi-ku, Yokohama City, Kanagawa 230-0045, Japan. ${ }^{4}$ Center for Integrative Medical Sciences, the Institute of Physical and Chemical Research (RIKEN), 1-7-22 Suehirocho, Tsurumi-ku, Yokohama City, Kanagawa 230-0045, Japan.

Received: 15 April 2018 Accepted: 4 July 2018

Published online: 05 November 2018

\section{References}

1. Mahdi H, Fisher BA, Kallberg H, Plant D, Malmstrom V, Ronnelid J, et al. Specific interaction between genotype, smoking and autoimmunity to citrullinated alpha-enolase in the etiology of rheumatoid arthritis. Nat Genet. 2009;41:1319-24.

2. Okada Y, Wu D, Trynka G, Raj T, Terao C, Ikari K, et al. Genetics of rheumatoid arthritis contributes to biology and drug discovery. Nature. 2014;506:376-81.

3. Trouw LA, Rispens T, Toes REM. Beyond citrullination: other posttranslational protein modifications in rheumatoid arthritis. Nat Rev Rheumatol. 2017;13:331-9.

4. Malmstrom V, Catrina Al, Klareskog L. The immunopathogenesis of seropositive rheumatoid arthritis: from triggering to targeting. Nat Rev Immunol. 2017;17:60-75.

5. Orr C, Vieira-Sousa E, Boyle DL, Buch MH, Buckley CD, Canete JD, et al. Synovial tissue research: a state-of-the-art review. Nat Rev Rheumatol. 2017;13:463-75.

6. Smith SL, Plant D, Eyre S, Barton A. The potential use of expression profiling: implications for predicting treatment response in rheumatoid arthritis. Ann Rheum Dis. 2013;72:1118-24

7. Giannopoulou EG, Elemento O, Ivashkiv LB. Use of RNA sequencing to evaluate rheumatic disease patients. Arthritis Res Ther. 2015;17:167.

8. Sanayama Y, Ikeda K, Saito Y, Kagami S, Yamagata M, Furuta S, et al. Prediction of therapeutic responses to tocilizumab in patients with rheumatoid arthritis: biomarkers identified by analysis of gene expression in peripheral blood mononuclear cells using genome-wide DNA microarray. Arthritis Rheumatol. 2014;66:1421-31.

9. Sellam J, Marion-Thore S, Dumont F, Jacques S, Garchon HJ, Rouanet S, et al. Use of whole-blood transcriptomic profiling to highlight several pathophysiologic pathways associated with response to rituximab in patients with rheumatoid arthritis: data from a randomized, controlled, open-label trial. Arthritis Rheumatol. 2014;66:2015-25.

10. Wright HL, Thomas HB, Moots RJ, Edwards SW. Interferon gene expression signature in rheumatoid arthritis neutrophils correlates with a good response to TNFi therapy. Rheumatology (Oxford). 2015; 54:188-93

11. Farh KK, Marson A, Zhu J, Kleinewietfeld M, Housley WJ, Beik S, et al. Genetic and epigenetic fine mapping of causal autoimmune disease variants. Nature. 2015:518:337-43.

12. Ishigaki K, Kochi Y, Suzuki A, Tsuchida Y, Tsuchiya H, Sumitomo S, et al. Polygenic burdens on cell-specific pathways underlie the risk of rheumatoid arthritis. Nat Genet. 2017:49:1120-5.

13. Ye H, Zhang J, Wang J, Gao Y, Du Y, Li C, et al. CD4 T-cell transcriptome analysis reveals aberrant regulation of STAT3 and Wnt signaling pathways in rheumatoid arthritis: evidence from a case-control study. Arthritis Res Ther. 2015;17:76.

14. Shen H, Goodall JC, Hill Gaston JS. Frequency and phenotype of peripheral blood Th17 cells in ankylosing spondylitis and rheumatoid arthritis. Arthritis Rheum. 2009;60:1647-56.

15. Esensten JH, Wofsy D, Bluestone JA. Regulatory $T$ cells as therapeutic targets in rheumatoid arthritis. Nat Rev Rheumatol. 2009:5:560-5.

16. He J, Tsai LM, Leong YA, Hu X, Ma CS, Chevalier N, et al. Circulating precursor CCR7(lo)PD-1(hi) CXCR5(+) CD4(+) T cells indicate Tfh cell activity and promote antibody responses upon antigen reexposure. Immunity. 2013;39:770-81. 
17. Sumitomo S, Nagafuchi Y, Tsuchida Y, Tsuchiya H, Ota M, Ishigaki K, et al. A gene module associated with dysregulated TCR signaling pathways in CD4(+) T cell subsets in rheumatoid arthritis. J Autoimmun. 2018;89:21-9.

18. He Y, Xu H, Liang L, Zhan Z, Yang X, Yu X, et al. Antiinflammatory effect of Rho kinase blockade via inhibition of NF-kappaB activation in rheumatoid arthritis. Arthritis Rheum. 2008;58:3366-76.

19. Bremer E, Abdulahad WH, de Bruyn M, Samplonius DF, Kallenberg CG, Armbrust W, et al. Selective elimination of pathogenic synovial fluid T-cells from rheumatoid arthritis and juvenile idiopathic arthritis by targeted activation of Fas-apoptotic signaling. Immunol Lett. 2011;138:161-8.

20. Langfelder P, Horvath S. WGCNA: an R package for weighted correlation network analysis. BMC Bioinf. 2008;9:559.

21. Kremer JM, Westhovens R, Leon M, Di Giorgio E, Alten R, Steinfeld S, et al. Treatment of rheumatoid arthritis by selective inhibition of T-cell activation with fusion protein CTLA4lg. N Engl J Med. 2003:349:1907-15.

22. Raterman HG, Vosslamber S, de Ridder S, Nurmohamed MT, Lems WF, Boers $M$, et al. The interferon type I signature towards prediction of non-response to rituximab in rheumatoid arthritis patients. Arthritis Res Ther. 2012;14:R95.

23. Vosslamber S, Raterman HG, van der Pouw Kraan TC, Schreurs MW, von Blomberg BM, Nurmohamed MT, et al. Pharmacological induction of interferon type I activity following treatment with rituximab determines clinical response in rheumatoid arthritis. Ann Rheum Dis. 2011;70:1153-9.

24. Thurlings RM, Boumans M, Tekstra J, van Roon JA, Vos K, van Westing $D M$, et al. Relationship between the type I interferon signature and the response to rituximab in rheumatoid arthritis patients. Arthritis Rheum. 2010;62:3607-14.

25. Koczan D, Drynda S, Hecker M, Drynda A, Guthke R, Kekow J, et al. Molecular discrimination of responders and nonresponders to antiTNF alpha therapy in rheumatoid arthritis by etanercept. Arthritis Res Ther. 2008:10:R50.

26. van Baarsen LG, Wijbrandts CA, Rustenburg F, Cantaert T, van der Pouw Kraan TC, Baeten DL, et al. Regulation of IFN response gene activity during infliximab treatment in rheumatoid arthritis is associated with clinical response to treatment. Arthritis Res Ther. 2010;12:R11.

27. Saito Y, Kagami S, Sanayama Y, Ikeda K, Suto A, Kashiwakuma D, et al. ATrich-interactive domain-containing protein $5 \mathrm{~A}$ functions as a negative regulator of retinoic acid receptor-related orphan nuclear receptor gammatinduced Th17 cell differentiation. Arthritis Rheumatol. 2014;66:1185-94.

28. Dennis G Jr, Holweg CT, Kummerfeld SK, Choy DF, Setiadi AF, Hackney JA, et al. Synovial phenotypes in rheumatoid arthritis correlate with response to biologic therapeutics. Arthritis Res Ther. 2014;16:R90.

29. Galligan CL, Baig E, Bykerk V, Keystone EC, Fish EN. Distinctive gene expression signatures in rheumatoid arthritis synovial tissue fibroblast cells: correlates with disease activity. Genes Immun. 2007:8:480-91.

30. Nakano K, Whitaker JW, Boyle DL, Wang W, Firestein GS. DNA methylome signature in rheumatoid arthritis. Ann Rheum Dis. 2013;72:110-7.

31. Ai R, Laragione T, Hammaker D, Boyle DL, Wildberg A, Maeshima K, et al. Comprehensive epigenetic landscape of rheumatoid arthritis fibroblast-like synoviocytes. Nat Commun. 2018;9:1921.

32. Blits $M$, Jansen $G$, Assaraf $Y G$, van de Wiel MA, Lems WF, Nurmohamed MT, et al. Methotrexate normalizes up-regulated folate pathway genes in rheumatoid arthritis. Arthritis Rheum. 2013;65:2791-802.

33. Boyle DL, Soma K, Hodge J, Kavanaugh A, Mandel D, Mease P, et al. The JAK inhibitor tofacitinib suppresses synovial JAK1-STAT signalling in rheumatoid arthritis. Ann Rheum Dis. 2015;74:1311-6.

34. Crow MK. Type I interferon in systemic lupus erythematosus. Curr Top Microbiol Immunol. 2007;316:359-86.

35. Bilgic $H$, Ytterberg SR, Amin S, McNallan KT, Wilson JC, Koeuth T, et al. Interleukin- 6 and type I interferon-regulated genes and chemokines mark disease activity in dermatomyositis. Arthritis Rheum. 2009;60:3436-46.

36. Bos CL, van Baarsen LG, Timmer TC, Overbeek MJ, Basoski NM, Rustenburg $F$, et al. Molecular subtypes of systemic sclerosis in association with anticentromere antibodies and digital ulcers. Genes Immun. 2009;10:210-8.

37. Taylor JC, Bongartz T, Massey J, Mifsud B, Spiliopoulou A, Scott IC, et al. Genome-wide association study of response to methotrexate in early rheumatoid arthritis patients. Pharmacogenomics J. 2018. https://doi.org/10. 1038/s41397-018-0025-5. [Epub ahead of print].

\section{Ready to submit your research? Choose BMC and benefit from:}

- fast, convenient online submission

- thorough peer review by experienced researchers in your field

- rapid publication on acceptance

- support for research data, including large and complex data types

- gold Open Access which fosters wider collaboration and increased citations

- maximum visibility for your research: over $100 \mathrm{M}$ website views per year

At BMC, research is always in progress.

Learn more biomedcentral.com/submissions 